\title{
Frequency of homologous blood transfusion in patients undergoing cleft lip and palate surgery
}

\author{
Wasiu L. Adeyemo, Mobolanle O. Ogunlewe, lbironke Desalu, Akinola L. Ladeinde, \\ Titilope A. Adeyemo, Bolaji O. Mofikoya, Olakunle O. Hassan, Alani S. Akanmu \\ Departments of Oral and Maxillofacial Surgery, Haematology \& Transfusion Medicine, Anaesthesia, Haematology and Blood \\ Transfusion, and Surgery, College of Medicine, University of Lagos
}

Address for correspondence: Dr. W.L Adeyemo, Department of Oral and Maxillofacial Surgery, College of Medicine, University of Lagos, Nigeria. E-mail: lanreadeyemo@yahoo.com

\section{ABSTRACT}

\begin{abstract}
Aim: The study aims to determine the frequency of homologous blood transfusion in patientsundergoing cleft lip and palate surgery at the Lagos University Teaching Hospital, Nigeria. Setting and Design: A prospective study of transfusion rate in cleft surgery conducted at the Lagos University Teaching Hospital, Nigeria. Material and Methods: One hundred consecutive patients who required cleft lip and palate surgery were recruited into the study. Data collected included age, sex and weight of patients, type of cleft defects, type of surgery done, preoperative haematocrit, duration of surgery, amount of blood loss during surgery, the number of units of blood cross-matched and those used. Each patient was made to donate a unit of homologous blood prior to surgery. Results: There were 52 females and 48 males with a mean age of $64.4 \pm 101.1$ months (range, 3-420 months). The most common cleft defect was isolated cleft palate (45\%) followed by unilateral cleft lip (28\%). Cleft palate repair was the most common procedure $(45 \%)$ followed by unilateral cleft lip repair (41\%). The mean estimated blood loss was $95.8 \pm 144.9 \mathrm{ml}$ (range, 2-800ml). Ten $(10 \%)$ patients $(C L=2 ; C P=5, B C L=1 ; C L P=2)$ were transfused but only two of these were deemed appropriate based on percentage blood volume loss. The mean blood transfused was $131.5 \pm$ $135.4 \mathrm{ml}$ (range, $35-500 \mathrm{ml}$ ). Six $(60 \%)$ of those transfused had a preoperative PCV of $<30 \%$. Only $4.9 \%$ of patients who had unilateral cleft lip surgery were transfused as compared with $50 \%$ for CLP surgery, $11 \%$ for CP surgery, and $10 \%$ for bilateral cleft lip surgery. Conclusions: The frequency of blood transfusion in cleft lip and palate surgery was $10 \%$ with a cross-match: transfusion ratio of 10 and transfusion index of 0.1. A "type and screen" policy is advocated for cleft lip and palate surgery.
\end{abstract}

\section{KEY WORDS}

Blood transfusion; cleft surgery; homologous transfusion

\section{INTRODUCTION}

lefts of the lip, alveolus and palate are among the most common congenital malformation of the head and neck. ${ }^{[1]}$ The prevalence per 1000 total birth of cleft lip and/or with cleft palate ranges from around two in Mongoloid populations to about
0.5 in Negroid groups, and in Caucasian populations the prevalence is about 1.2 per 1000 total birth. ${ }^{[2]}$

The problems/challenges associated with cleft lip and palate deformities vary depending on the degree and location of the defect. These include feeding difficulties, speech and language delays, ear infections/hearing 
loss, aesthetic problem, dental anomalies, psychosocial problems and reduced quality of life. ${ }^{[3-5]}$ To correct the problems, these defects need to be repaired as soon as the patient is fit for surgery.

In our institution, patients undergoing CLP surgery and other maxillofacial surgical procedures have traditionally been required to look for a replacement donor to donate at least 1 unit of homologous blood before surgery and this is preoperatively cross-matched, in case significant blood loss is expected. This practice is expensive, time consuming, and may in several cases, be unnecessary. ${ }^{[6]}$ The over-ordering of cross-matched blood to cover operation can result in blood shortages. It is also costly, and can never be free of risk. The risks associated with blood transfusion are well documented in the literature..$^{[7,8]}$

A number of surgical procedures including hysterectomy, colostomy, thyroidectomy and a few others have been shown to seldom require transfusion, ${ }^{[9]}$ and blood is not usually cross-matched and tied down. However, for these procedures, the policy of "Type and Screen" is usually adopted such that blood can be quickly made available if for any reason the surgical intervention eventually demands a blood transfusion. ${ }^{[10]}$ The procedure of type and screen requires that: i) the $\mathrm{ABO}$ and Rhesus type of the patient is determined; ii) the patient serum is also screened for presence of unexpected allo-antibodies. If the patient does not have any allo-antibody it will be safe to select $\mathrm{ABO}$ and Rhesus donor blood compatible with the patient if there is a need for transfusion during or following surgery without a necessity for cross-matching. Such a non-cross-matched $\mathrm{ABO}$ and Rhesus identical blood can be released with $99.9 \%$ assurance of safety as long as the patient has no unexpected antibody. ${ }^{[11]}$

The aim of this study was to determine the frequency of homologous blood transfusion in patients undergoing cleft lip and/or palate surgery at the Lagos University Teaching Hospital, Nigeria, with a view to setting a guideline for blood transfusion protocol in CLP surgical procedures.

\section{MATERIAL AND METHODS}

One hundred consecutive patients who had CLP surgery done at the Lagos University Teaching Hospital between
March 2007 and November 2008 were recruited into the study. Data collected included age, sex and weight of patients, type of cleft defects, type of surgery done, preoperative haematocrit, duration of surgery, amount of blood loss during surgery, and amount of blood transfused.

\section{Anaesthetic and surgical technique}

All cases were done under general anaesthesia. Induction was either inhalational with incremental halothane or intravenous using thiopentone or propofol. When the depth of anaesthesia was judged to be adequate, the trachea was intubated with the appropriate sized southpolar (for cleft lip repair only) or re-inforced (for palatal surgery) endotracheal tube under deep inhalational anaesthesia or muscle relaxants using external laryngeal pressure if needed. Maintenance of anaesthesia was with isoflurane and all patients were ventilated after administration of a muscle relaxant. Analgesia was provided with fentanyl, paracetamol, diclofenac or pethidine.

The surgical site was infiltrated with adrenaline $(1: 100,000)$ before making the incision. Unilateral cleft lip was repaired using either Millard's rotation advancement technique or Tennison-Randall triangular technique. Bilateral cleft lip was repaired using Fork technique, and cleft palate repair was done with von Langenbeck technique.

\section{Blood donation, blood loss and transfusion}

Each patient was made to look for a replacement donor to donate 1 unit of blood prior to surgery. For all the patients, 1 unit of homologous blood was cross-matched for the surgery. Blood loss was calculated by weighing gauze, measuring suctioned blood, and adjusting for the volume of irrigation solution used during the operation. The decision to transfuse was made at the discretion of the anaesthetist. Afterward, cross-match-to-transfusion ratio (the index of efficiency of ordering and usage), transfusion index (average number of units transfused for a given procedure) and probability of transfusion were calculated. Blood volume was calculated for each patient and percentage blood volume loss was calculated

\section{Data analysis}

Data was analysed using the SPSS for Windows (version 12.0; SPSS Inc, Chicago, IL) statistical software package; 
and presented in descriptive and tabular forms. Test of significance was used as appropriate. Correlation between duration of operation and blood loss was analyzed with simple regression. $P$ value was set at $\leq 0.05$.

\section{RESULTS}

There were 52 females and 48 males with a mean age of $64.4 \pm 101.1$ months (range, 3-420 months). The most common cleft defect was isolated CP (45\%) followed by unilateral cleft lip (28\%) [Table 1]. CP repair was the most common procedure (45\%) followed by unilateral cleft lip repair; UCL (41\%) [Table 2]. Primary and secondary surgical repairs were done in 85 and 15 patients respectively. A hundred units (1 unit per patient) of homologous blood were donated and cross matched for surgery.

Preoperative haematocrit values ranged between 22 and $43 \%$ (Mean $=30.8 \%, S D=4$ ). The mean estimated blood loss was $95.8 \pm 144.9 \mathrm{ml}$ (range, 2-800ml). Most patients $(77 \%)$ lost between $2-100 \mathrm{ml}$ of blood. Table 3 shows blood loss in different types of cleft surgery. The mean estimated blood loss in unilateral cleft lip surgery was not significantly different from that of bilateral cleft lip surgery $(P=0.22)$ but significantly lower than those of cleft palate surgery and combined cleft lip/palate surgery $(P=0.000)$.

Ten (10\%) patients $(\mathrm{CL}=2 ; \mathrm{CP}=5, \mathrm{BCL}=1 ; \mathrm{CLP}=2)$ had blood transfusion. The mean blood transfused was 131.5 $\pm 135.4 \mathrm{ml}$ (range, $35-500 \mathrm{ml}$ ). In nine of the 10 patients, volume of blood transfused ranged between 35 and $140 \mathrm{ml}$. Only one female adult patient (CP) who lost $800 \mathrm{ml}$ of blood received 1 unit $(500 \mathrm{ml})$ of blood perioperatively

Table 1: Types of cleft defects

\begin{tabular}{lc}
\hline Type of cleft defect & Number (\%) \\
\hline Unilateral cleft lip & $28(28)$ \\
Bilateral cleft lip & $7(7)$ \\
Unilateral cleft lip and palate & $13(13)$ \\
Bilateral cleft lip and palate & $7(7)$ \\
Isolated cleft palate & $45(45)$ \\
Total & 100 \\
\hline
\end{tabular}

[Table 4]. Six (60\%) of those transfused had a preoperative haematocrit of $<30 \%$. Only $4.9 \%$ of patients who had unilateral cleft lip surgery were transfused as compared with $50 \%$ for CLP surgery, $11 \%$ for CP surgery, and $10 \%$ for bilateral cleft lip surgery. There was no significant difference in transfusion rate in patients with preoperative haematocrit of less than $30 \%$ and those with more than $30 \%$ [Table 5].

Estimated duration of surgery ranged between 20 minutes and 240 minutes (mean $=91.6 \quad \mathrm{SD}=37.2$ minutes). The duration of surgery in cleft lip procedures was significantly lower than those of cleft palate and combined cleft lip and palate procedures $(P=0.001)$. Simple regression analysis showed significant positive correlation between duration of surgery and blood loss ( $\mathrm{n}=100, \mathrm{R}=0.472$, adjusted $\mathrm{R}^{2}=0.215, P=0.000$ ).

Table 6 shows the estimated blood volume, amount of blood loss and appropriateness or otherwise of blood transfusion. Only two transfusions were considered appropriate based on percentage blood volume loss. The cross-match-to-transfusion ratio was 10 overall, 20.5 for unilateral cleft lip surgery and 2.0 for cleft lip and palate surgery [Table 7]. The transfusion index for unilateral cleft lip surgery was 0.05 and 0.5 for cleft lip and palate surgery [Table 7]. The overall probability of transfusion and blood-ordering quotient in cleft lip and/or palate surgery was $2 \%$ and 10 respectively. No mortality was recorded during the study. No transfusion reaction was recorded in those transfused.

\section{DISCUSSION}

The ultimate goal of evidence based clinical research is to formulate a clinical practice guideline. To date, there are no reports on transfusion rate in cleft lip and/or palate in the literature. However, many authors have reported rate of blood transfusion in other more extensive maxillofacial surgical procedures to be low. ${ }^{[12,13]}$ Therefore, there is a need to ascertain the need for blood transfusion in cleft lip and/or palate surgery.

Table 2: Transfusion rate in different types of cleft surgery

\begin{tabular}{lcccc}
\hline Type of cleft surgery & Total & Not transfused & Transfused & Transfusion rate \% \\
\hline Unilateral cleft lip & 41 & 39 & 2 & 4.9 \\
Bilateral cleft lip & 10 & 9 & 1 & 10 \\
Cleft palate & 45 & 40 & 5 & 11 \\
Cleft lip and palate & 4 & 2 & 2 & 50 \\
Total & 100 & 90 & 10 & 10 \\
\hline
\end{tabular}


Table 3: Types of cleft surgery and blood loss

\begin{tabular}{lcc}
\hline \multirow{2}{*}{$\begin{array}{l}\text { Type of cleft surgery } \\
\text { (number) }\end{array}$} & \multicolumn{2}{c}{ Blood loss (mI) } \\
\cline { 2 - 3 } & Range & Mean (SD) \\
\hline Unilateral cleft lip (41) & $2-300$ & $32.6(52.9)$ \\
Bilateral cleft lip (10) & $5-50$ & $25.7(16.2)$ \\
Cleft palate $\quad(45)$ & $10-800$ & $137.9(142.1)$ \\
Cleft lip and palate (4) & $100-800$ & $445(314.2)$ \\
\hline
\end{tabular}

Table 5: Transfusion rate and preoperative hematocrit value

\begin{tabular}{lccc}
\hline Hematcrit & Transfused & Not transfused & Total \\
\hline$<30 \%$ & 6 & 31 & 37 \\
$\geq 30 \%$ & 4 & 59 & 63 \\
\hline$P=0.112$ & &
\end{tabular}

$P=0.112$

Table 7: Transfusion indices

\begin{tabular}{lc}
\hline & Value $^{*}$ \\
\hline Cross-match: transfusion ratio & 10 \\
- UCL & 20.5 \\
- BCL & 10 \\
- CP & 9 \\
- CLP & 2 \\
Transfusion index & 0.1 \\
- UCL & 0.05 \\
- BCL & 0.1 \\
- CP & 0.1 \\
- CLP & 0.5 \\
Probability of transfusion & $2 \%$ \\
Blood-ordering quotient & 10 \\
- UCL & 20.5 \\
- BCL & 10 \\
- CP & 9 \\
- CLP & 2 \\
\hline
\end{tabular}

*Values were calculated based on units of blood opened for transfusion

The 2000-2001 annual report of the serious hazards of transfusion (SHOT) Steering Group (United Kingdom) highlighted the serious hazards of blood transfusion. ${ }^{[14]}$ Most morbidity or mortality results from giving the wrong blood or blood products rather than transmission of infection. The National Health Service, United Kingdom executive paper on "Better blood transfusion" recommends that blood should only be given when necessary to save life or prevent deterioration, not simply to hasten recovery. ${ }^{[15]}$ Ordering of too much cross-matched blood to cover operations can result in shortages of blood, wasted laboratory time, and it is also costly. Risk free transfusion whether it be homologous or autogenous blood does not exist. ${ }^{16]}$

In the present study, the overall mean estimated blood loss was $95.8 \pm 144.9 \mathrm{ml}$; and most patients $(77 \%)$ lost between $2-100 \mathrm{ml}$ of blood during surgery. Hence, CLP surgery may be classified a "small/low volume" blood loss surgery. Estimated blood loss in unilateral cleft lip surgery was not significantly different from that in bilateral cleft
Table 4: Characteristics of patients who were transfused

\begin{tabular}{lccccc}
$\begin{array}{l}\text { Age } \\
\text { (months) }\end{array}$ & Sex & Surgery & $\begin{array}{c}\text { Preop } \\
\text { PCV }\end{array}$ & $\begin{array}{c}\text { Blood } \\
\text { loss }\end{array}$ & $\begin{array}{c}\text { Amount } \\
\text { transfused }\end{array}$ \\
\hline 4 & F & CL & 25 & $30 \mathrm{ml}$ & $40 \mathrm{ml}$ \\
11 & F & CL & 26 & $30 \mathrm{ml}$ & $35 \mathrm{ml}$ \\
16 & $\mathrm{M}$ & $\mathrm{BCL}$ & 23 & $40 \mathrm{ml}$ & $40 \mathrm{ml}$ \\
48 & $\mathrm{M}$ & $\mathrm{CL}$ & $\mathrm{P} 32$ & $100 \mathrm{ml}$ & $100 \mathrm{ml}$ \\
14 & $\mathrm{M}$ & $\mathrm{CP}$ & 29 & $100 \mathrm{ml}$ & $100 \mathrm{ml}$ \\
420 & $\mathrm{~F}$ & $\mathrm{CP}$ & 31 & $800 \mathrm{ml}$ & $500 \mathrm{ml}$ \\
32 & $\mathrm{~F}$ & $\mathrm{CP}$ & 29 & $100 \mathrm{ml}$ & $140 \mathrm{ml}(\mathrm{HbSS})$ \\
12 & $\mathrm{~F}$ & $\mathrm{CP}$ & 27 & $200 \mathrm{ml}$ & $140 \mathrm{ml}$ \\
27 & $\mathrm{M}$ & $\mathrm{CP}$ & 30 & $100 \mathrm{ml}$ & $120 \mathrm{ml}$ \\
60 & $\mathrm{M}$ & $\mathrm{CLP}$ & 34 & $280 \mathrm{ml}$ & $100 \mathrm{ml}$ \\
\hline
\end{tabular}

Table 6: Appropriateness of blood transfusion based on patients' blood volume and blood loss

\begin{tabular}{lccl} 
Weight $(\mathbf{K g})$ & EBV $(\boldsymbol{m l})$ & $\begin{array}{c}\text { Blood loss } \\
\text { (\% blood volume) }\end{array}$ & Remark \\
\hline 3.9 & 312 & $30 \mathrm{ml}(9.6)$ & Inappropriate \\
7.3 & 584 & $30 \mathrm{ml}(5.1)$ & Inappropriate \\
7.7 & 616 & $40 \mathrm{ml}(6.5)$ & Inappropriate \\
15 & 1050 & $100 \mathrm{ml}(9.5)$ & Inappropriate \\
9.4 & 752 & $100 \mathrm{ml}(13.3)$ & Inappropriate \\
63 & 4410 & $800 \mathrm{ml}(18.1)$ & Inappropriate \\
14 & 980 & $100 \mathrm{ml}(10.2)$ & Inappropriate \\
8.5 & 680 & $200 \mathrm{ml}(29.4)$ & Appropriate \\
15 & 1050 & $100 \mathrm{ml}(9.5)$ & Inappropriate \\
16 & 1120 & $280 \mathrm{ml}(25)$ & Appropriate \\
\hline EBV=estimated blood volume & &
\end{tabular}

lip surgery; but was significantly lower than that in cleft palate surgery and combined cleft lip/palate surgery. This may be explained on the basis of duration of surgery. Estimated duration of unilateral/bilateral cleft lip surgery was significantly lower than those of cleft palate surgery and combined CL/P surgery; and a significant positive correlation was found between duration of surgery and blood loss.

It is noteworthy that the local anaesthetic agent (lignocaine) containing 1:200,000 adrenaline was routinely injected before surgical incisions were made in all cases performed in the present study. This was also responsible for the relatively small amount of blood loss during surgery. The use of vasoconstrictor agent to reduce bleeding is a recommended approach to the conservation of blood. ${ }^{[17]}$ Other recommended approaches to reduction of blood loss during surgery include hypotensive anaesthesia, $20-30^{\circ}$ head up tilt, perioperative use of tranexamic acid, and ligation and diathermy of vessels. ${ }^{[18]} \mathrm{A}$ head up tilt of the patient improves diaphragmatic function and respiratory status while reducing venous return, leading to a fall in cardiac output and mean arterial pressure. ${ }^{[18]}$ 
In the present study, frequency of transfusion in cleft lip and/or palate surgery was $10 \%$. The transfusion rate was highest in combined cleft lip and palate surgery (50\%) and cleft palate surgery (11\%) and lowest in unilateral (4.9\%) and bilateral cleft lip (10\%) surgeries. Blood-ordering tariffs can be calculated using the principle that those operations that rarely require blood can be safely done when policy of type and screen is adopted. ${ }^{[16]}$ Rationalised ordering of blood is safe and also saves money. ${ }^{[16]}$

In view of low blood transfusion rate in cleft lip surgery, preoperative homologous blood donation and crossmatch for cleft lip surgery especially in children with $\mathrm{Hb}$ of $\geq 10 \mathrm{~g} / \mathrm{dl}$ may not be necessary. This study also demonstrated that there is no indication to crossmatch blood for all patients undergoing cleft lip and palate surgery. It should be sufficient to type and screen blood preoperatively for cleft palate surgery; this can be made available quickly if required. In patients with low haematocrit undergoing cleft lip surgery, a transfusion need may be predicted and have a cross-match performed preoperatively. Pre-operative grouping and crossmatching of blood may be necessary in case of combined cleft lip and palate surgery.

In the present study, there was no significant difference in transfusion rates in patients with preoperative haematocrit of less than $30 \%$ and those with more than $30 \%$. This implies that homologous blood transfusion in the present series was not dependent on preoperative haematocrit value. A patient who had underwent cleft lip repair and who had the lowest preoperative haematocrit $(22 \%)$ in the present study, received no blood transfusion. This can be ascribed to the fact that with a preoperative low haematocrit, the amount of red cells per unit volume of blood lost during surgery is minimal and this forms the rationale for presurgical haemodilution. Length of surgery, based on the findings in this study, seems a greater risk factor for blood transfusion rather than low haematocrit in an otherwise healthy patient.

Measures like acute normovolaemic haemodilution, being currently explored, and which may be of use in adult cleft palate surgery show great promise. ${ }^{[16]}$ However, they incur additional cost and require additional time for the collection and storage. ${ }^{[16]}$

The cross-match: transfusion ratio (CTR), which is the number of units cross-matched for a procedure divided by the total number of units transfused, and is an index of the efficiency of ordering and use of blood, and it should be less than 2.5. ${ }^{[16]}$ In this study, CTR was 20.5, 10.0, 9.0 and 2.0 for unilateral cleft lip, bilateral cleft lip, cleft palate and combined cleft lip and palate surgeries respectively.

The transfusion index (TI) is a measure of the amount of blood used for a given procedure. $\mathrm{TI}$ is an average number of units transfused for a given procedure. A value of less than 0.5 suggests that cross-matched blood is unlikely to be required. ${ }^{[16]}$ In the present study, $\mathrm{TI}$ was $0.05,0.1,0.1$ and 0.5 for unilateral cleft lip, bilateral cleft lip, cleft palate and combined cleft lip and palate surgeries respectively.

The overall probability of transfusion (PoT) in the present study was $2 \%$. PoT is a ratio of the number of appropriate transfusions for the total number of operations. A PoT of less than $30 \%$ is an indication for grouping and saving only. ${ }^{[16]}$ The PoT of $2 \%$ in the present study supports a group and save policy for CLP (and/or) surgery.

The blood-ordering quotient (BOQ) is the number of cross-matched units of blood per patient divided by the number of units transfused per patient. ${ }^{[16,19]}$ The value of the CTR as a gross determination of over-ordering has been challenged, and the use of BOQ recommended. ${ }^{[19]}$ A BOQ above 1.5 is considered unacceptable and it is advised that these procedures be grouped and saved. BOQ was 20.5, 10.0, 9.0 and 2.0 for unilateral cleft lip, bilateral cleft lip, CP and combined CLP surgeries respectively. These values were not different from CTR values because all the patients had 1 unit of blood cross matched preoperatively and kept ready.

Of the 10 patients who had blood transfusion, transfusion was deemed inappropriate in eight and appropriate in two based on percentage blood volume loss. Available evidence does not support the use of single criterion for transfusion such as haemoglobin concentration of $<10 \mathrm{~g} /$ dl. No single measure can replace good clinical judgment and accurate monitoring in the peri-operative period. The decision to transfuse should take into consideration the expected level and duration of anaemia, the intravascular volume, the duration of operation and the probability of massive blood loss. ${ }^{[16,18]}$ In the present series, it was suspected that in a few circumstances, blood was given by a junior (trainee) anaesthetist just because it was available. If transfusion was done for reason of volume depletion, and not for oxygenation, crystalloid should have sufficed in most cases. But, if blood was transfused due to reduced oxygenation (reduced haemoglobin 
concentration), and not for volume depletion, packed red cell would have sufficed. The risk associated with transfusion has been reported to be less in packed red cell than in whole blood. ${ }^{[10]}$ There is less risk of volume overload, plasma antigens load and also allergic reactions.

\section{CONCLUSION}

CLP surgery is a "small volume" blood loss surgery. The frequency of blood transfusion in cleft lip and/or palate surgery was $10 \%$. Only two patients were considered to be appropriately transfused based on blood volume loss. Patients were most commonly transfused for cleft palate surgery and least commonly transfused for cleft lip surgery. In view of low blood transfusion rate in cleft lip surgery, preoperative homologous blood donation for cleft lip surgery especially in children with $\mathrm{Hb}$ of $\geq 10 \mathrm{~g} / \mathrm{dl}$ may not be necessary. This study demonstrates that there is no indication to cross-match one unit of blood for all patients undergoing cleft lip and palate surgery. It is sufficient to group and save one unit of blood preoperatively for cleft palate surgery; this can be made available quickly if required. In patients with low haematocrit, a transfusion need may be predicted and have a cross-match performed preoperatively.

\section{REFERENCES}

1. Sivertsen A, Wilcox A, Johnson GE, Abyholm F, Vindenes HA, Lie RT. Prevalence of major anatomic variations in oral clefts. Plast Reconstr Surg 2008;121:587-95.

2. Iregbulem LM. The incidence of cleft lip and palate in Nigeria. Cleft Palate J 1982;19:201-5.

3. Kapp-Simon KA. Psychological issues in cleft lip and palate. Clin Plast Surg 2004;31:347-52.

4. Nargozian C. The airway in patients with craniofacial abnormalities. Paediatr Anaesth 2004;14:53-9.

5. Peterson-Falzone SJ. Speech outcomes in adolescents with cleft lip and palate. Cleft Palate Craniofac J 1995;32:125-8.

6. Khan MS. Blood loss in orthognathic procedures--is there an indication to cross match? Oral Surg Oral Med Oral Pathol Oral Radiol Endod 2003;96:655-6.

7. Otsubo $\mathrm{H}$, Yamaguchi K. Current risks in blood transfusion in Japan. Jpn J Infect Dis 2005;61:427-33.

8. Rawn J. The silent risks of blood transfusion. Curr Opin Anaesthesiol 2008;21:664-8.

9. Walker RH, Hoppe PA, Judd WJ. Technical manual of the American Association of Blood Bank. Virginia: AABB: 1990. p. 269.

10. Boral LI, Henry JB. The type and screen: A safe alternative and supplement in selected surgical procedures. Transfusion 1977;17:163-68.

11. Friedman BA, Oberman HA, Chadwick AR, Kingdom KI. The maximum surgical blood order schedule and surgical blood use in the US. Transfusion 1976;16:380-7.

12. Moenning JE, Bussard DA, Lapp TH, Garrison BT. Average blood loss and the risk of requiring perioperative blood transfusion in 506 orthognathic surgical procedures. J Oral Maxillofac Surg 1995;53:880-3.

13. Gong SG, Krishnan V, Waack D. Blood transfusions in bimaxillary orthognathic surgery: Are they necessary? Int J Adult Orthodon Orthognath Surg 2002;17:314-7.

14. Stainsby D, Jones H, Asher D, Atterbury C, Boncinelli A, Brant L.et al. Serious hazards of transfusion: A decade of hemovigilance in the UK. Transfusion Med Rev 2006;20:273-82.

15. NHS Executive. Better blood transfusion. London: Department of Health; 1998 [HSC 1998/224]

16. Dhariwal DK, Gibbons AJ, Kittur MA, Sugar AW. Blood transfusion requirements in bimaxillary osteotomies. $\mathrm{Br} \mathrm{J}$ Oral Maxillofac Surg 2004;42:231-5.

17. Ueki K, Marukawa K, Shimada M, Nakagawa K, Yamamoto $\mathrm{E}$. The assessment of blood loss in orthognathic surgery for prognathia. J Oral Maxillofac Surg 2005;63;350-54.

18. Kurian $A$, Ward-Booth $P$. Blood transfusion and orthognathic surgery-a thing of the past? $\mathrm{Br} \mathrm{J}$ Oral Maxillofac Surg 2004;42:369-70

19. Mead JH, Anthony CD, Sattler M. Haemotherapy in elective surgery. An incidence report, review of the literature, and alternatives for guideline appraisal. Am J Clin Pathol 1980;74: 223-7.

Source of Support: Nil, Conflict of Interest: None declared. 